\title{
Membrane of the Rough Endoplasmic Reticulum
}

National Cancer Institute

\section{Source}

National Cancer Institute. Membrane of the Rough Endoplasmic Reticulum. NCI

Thesaurus. Code C33084.

A lipid bilayer enclosing the part of the endoplasmic reticulum that has ribosomes located on the cytoplasmic-facing membrane. 